\title{
Enzymatic heterozygosity and morphological variance in synthetic populations of Drosophila melanogaster
}

\author{
Gloria BLANCO LIZANA and J.A. SANCHEZ PRADO \\ Departamento de Genética, Universidad de Oviedo, Asturias, Spain
}

\begin{abstract}
Summary
Several reports have shown a negative correlation between allozyme heterozygosity and morphological variance and asymmetry. In this work, carried out on synthetic populations of Drosophila melanogaster, we have tried to find out if a relationship can be established between the variability (and symmetry level) of 4 morphometric characters and homozygosity for 5 enzymatic loci. Our results point to a positive correlation between morphological variability (and asymmetry) and homozygosis for the enzymatic loci. In addition, heterozygosity of other loci also influenced developmental stability.
\end{abstract} nogaster.

Key words : Morphological variance, enzymatic polymorphism, homeostasis, Drosophila mela-

\section{Résumé}

Hétérozygotie enzymatique et variance morphologique dans des populations synthétiques de Drosophila melanogaster.

Plusieurs expériences montrent qu'un taux élevé d'hétérozygotie (de l'individu ou de la population) est généralement associé à une faible variance morphologique et un faible degré d’asymétrie. Dans ce travail, réalisé dans des populations synthétiques de Drosophila melanogaster, nous avons essayé de voir s'il était possible d'établir une relation entre la variabilité (et l'asymétrie) de 4 caractères morphométriques et le taux d'homozygotie déterminé sur 5 locus enzymatiques. Nos résultats indiquent une corrélation positive entre variabilité (et asymétrie) morphologique et taux d'homozygotie déterminé sur les locus enzymatiques analysés. De plus, le taux d'homozygotie du reste du génome influe aussi sur la stabilité du développement.

Mots clés: Variance morphologique, polymorphisme enzymatique, homéostasie, Drosophila melanogaster. 


\section{Introduction}

Recently a lot of data have been put forward showing that morphological variability and asymmetry decrease with heterozygosity of enzyme polymorphisms (MrTton \& Grant, 1984). For example, Mitron (1978) examined 3 populations of Fundulus heteroclitus for 7 morphological characters and 5 polymorphic enzyme loci, and found that heterozygotes tend'ed to have lower phenotypic variation than homozygotes. EANES (1978) came to a similar conclusion after examining 6 polymorphic loci and 2 morphological traits in the monarch butterfly, Danaus plexippus. Enzyme heterozygosity has been reported as associated with either growth rate or developmental stability in a wide range of organisms : birds (Fleischer et al., 1983), shellfish (SingH \& Zouros, 1978 ; Zouros et al., 1980 ; Koehn \& Shunway, 1982), salamanders (Pierce \& Mitton, 1982), fish (Vrijenhoeck \& Lerman, 1982), plants (Knowles \& Mitton, 1980 ; Mitton et al., 1981 ; El-Kassaby, 1982) and insects (Gunawan, 1981 ; BiEmont, 1983). However, there are a few results where these correlations were not found (HANDFORD, 1980 ; MCANDREW et al., 1982).

Studies on symmetry were carried out on morphological characters with bilateral distribution (Soule, 1979 ; KAT, 1982 ; LEARY et al., 1983 ; BIEMONT, 1983), because bilateral symmetry is a direct measure of developmental homeostasis, which is the main cause to which several authors, according to the classical work of LERNER (1954), attribute this relationship. In fact, if developmental homeostasis is defined as the capability of an organism to form an average phenotype in the face of external perturbations (LERNER, 1954), a small deviation from bilateral symmetry should constitute a reasonable measure of a decrease in homeostasis (Soule, 1967 and 1979).

Generally, the authors found it difficult to account for their finding that enzyme heterozygotes are less variable than homozygotes. In particular they found it surprising that such effects should be observed when only 5 or 6 loci were screened out of the thousands expected to be polymorphic. In recent papers different possible mechanisms are suggested. Kobliansky \& Livshits (1983), in human populations, and Leding et al. (1983), in pitch pine, are inclined to attribute the correlation to inbreeding. LEARY et al. (1984) considered that the particular enzyme locus itself influenced development. MitToN \& KoEHN (1985), propose that enzyme heterozygosity is linked to energy budgets of individuals and that the developmental stability reflects the energy balance. The explanation of why they exhibit greater developmental stability is that heterozygotes have, on the average, a higher positive energy balance, and these genotypes should be less affected during development by stressing environmental variations.

These results are also germane to the controversy concerning the adaptive significance of protein polymorphisms. If the negative correlation between enzyme heterozygosity and morphological variability and asymmetry is, in fact, general, these correlations cannot be in agreement with a neutral theory for the origin and maintenance of enzyme polymorphisms. The variation at these enzymatic loci should be maintained, at least in part, by a heterozygous advantage (MCANDREw et al., 1982 ; LeARY et al., 1984).

In our work, carried out on synthetic populations of Drosophila melanogaster, we have examined the relationship between the variability and symmetry of morphometric characters and degree of homozygosity for 5 biochemical loci chosen at random. In addition, our experimental design allowed us to measure the influence of heterozygosity of the background genotype. 


\section{Materials and methods}

Using a balanced lethal stock (CyL/Pm TM3/Pr), isochromosomal lines for chromosomes II and III were established from a natural population of Drosophila melanogaster recently caught in the wild.

Of these lines, 117 were chosen because they did not present inversions, and were homozygous for the different allelic variants of the 5 enzymatic loci analyzed ( $A d h$, Aph-1, Est-6, $\alpha-G p d h$ and Lap-D). Taken as a whole these lines constitute what we shall call highly homozygous population (HHP). The HHP lines, with the same genotype for the 5 enzymatic loci, were crossed and maintained by mass-culture. The 8 subpopulations so formed, altogether, constitute what we shall term partially homozygous populations (PHP). In these PHP, the 5 enzymatic loci were in a homozygous state, but the background genotype of the natural population was partially reconstructed, because in all cases 10 or more HHP lines were pooled (NeI et al., 1975). Finally, the PHP lines with complementary genotypes for the 5 enzymatic loci were crossed; the offspring of these 4 possible crosses were immediately analyzed, and will be referred to as heterozygotes (HET).

The numbers of dorsocentral, scutellar, sternopleural and fifth abdominal sternite bristles have been studied as morphometric characters. All but the last of these are bilateral characters and they exhibit fluctuating asymmetry in the populations because the difference between a character on the left and right sides of individuals is normally distributed about a mean of zero. In these cases the bristle numbers were determined for the left and right sides on every individual. The individuals were then classified according to the absolute values of the difference between bristle number on the right and left sides.

We calculated the morphological variance $\left(\mathrm{s}^{2}\right)$ over all the individuals sampled in each class (HHP, PHP and HET) ; the asymmetry percentage (A) is the average deviation shown by the individuals in each class and the symmetry variation range (D) represents the minimum and maximum values of asymmetry found in each class. Moreover, we know that the homozygotes for the different electromorphs do not differ from each other with respect to the average values of any of these morphometric characters (Blanco \& RuBIo, 1983).

Horizontal starch gel electrophoresis was carried out with 12 p. 100 starch. Flies were homogenized in $0.01 \mathrm{ml}$ of gel starch buffer, using the method of JoHnson (1964). References of buffer and stain systems utilized are indicated in table 1.

TABLE 1

Biochemical loci, buffer and stain systems utilized.

\begin{tabular}{|c|c|c|c|}
\hline Enzyme systems & Abbreviation & Chromosome & References \\
\hline$\alpha$-Glycerophosphate dehydrogenase & $\alpha-G p d h$ & II $; 17.8$ & GRELL (1967) \\
\hline Alcohol dehydrogenase $\ldots \ldots \ldots$ & $A d h$ & II ; 50.1 & GRELL et al. (1965) \\
\hline Esterase $-6 \ldots \ldots$ & Est-6 & III ; 36.8 & WRIGHT (1963) \\
\hline Alkaline phosphatase & Aph-1 & III ; 46.3 & WALLIS \& Fox (1968) \\
\hline Leucine aminopeptidase $\ldots \ldots \ldots$ & Lap-D & III ; 98.3 & SAKAl et al. (1969) \\
\hline
\end{tabular}




\section{Results and discussion}

The null hypothesis tested here is that heterozygous individuals for the 5 enzymatic loci have the same level of symmetry and morphological variance as the individuals homozygous for the same loci. Table 2 shows the variance of morphometric characters in the 3 classes of populations analyzed, and table 3 shows the results on bilateral symmetry. The values of asymmetry (A), were compared with a t-test corrected for unequal variances, and the morphological variances by a one-tailed F-test (SoKAL \& RoHLF, 1979). The sample size (n) is the number of individuals analyzed in each population, taken from all the lines of each class. In all cases the HHP individuals showed both the greatest variance for the 4 morphometric characters analyzed (tabl. 2) and a greater deviation with respect to the bilateral symmetry (tabl. 3). On the other hand, the HET individuals displayed the least variance and the greatest degree of symmetry; 11 of the 14 comparisons made between both classes of individuals were

\section{TABLE 2}

Comparison of morphological variances for heterozygotes and homozygotes classes of $\mathrm{D}$. melanogaster.

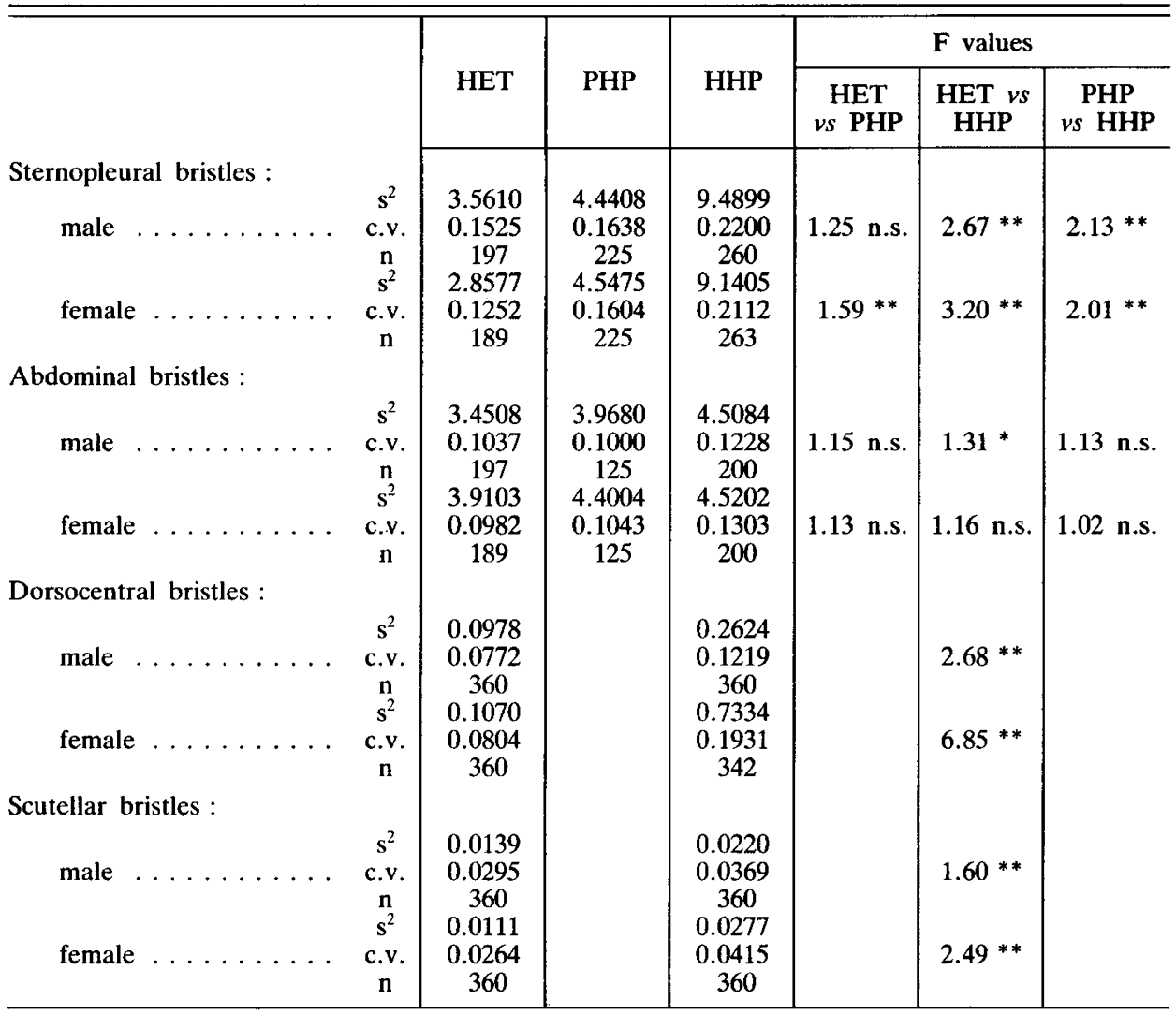

$\mathrm{s}^{2}=$ variance $;$ c.v. $=$ coefficient of variation $; n=$ sample size.

Differences among variances were tested with respect to the null hypothesis of no differences between variances.

${ }^{*} \mathrm{P}<0.05 ;{ }^{* *} \mathrm{P}<0.01 ;$ n.s. $=$ no significant. 
statistically significant (tabl. 2 and 3). The PHP individuals showed intermediate variance and symmetry values (tabl. 2 and 3 ) ; they differ significantly from the HET in 2 of the 6 comparison made and from the HHP in 4 of the 6 comparisons (tabl. 2 and 3 ). The same results were obtained using the magnitude of asymmetry. In 2 of the 3 characters the HET showed the least symmetry variation range (tabl. 3 and fig. 1).

TABLE 3

Comparison of average asymmetry for heterozygotes and homozygotes classes of D. melanogaster.

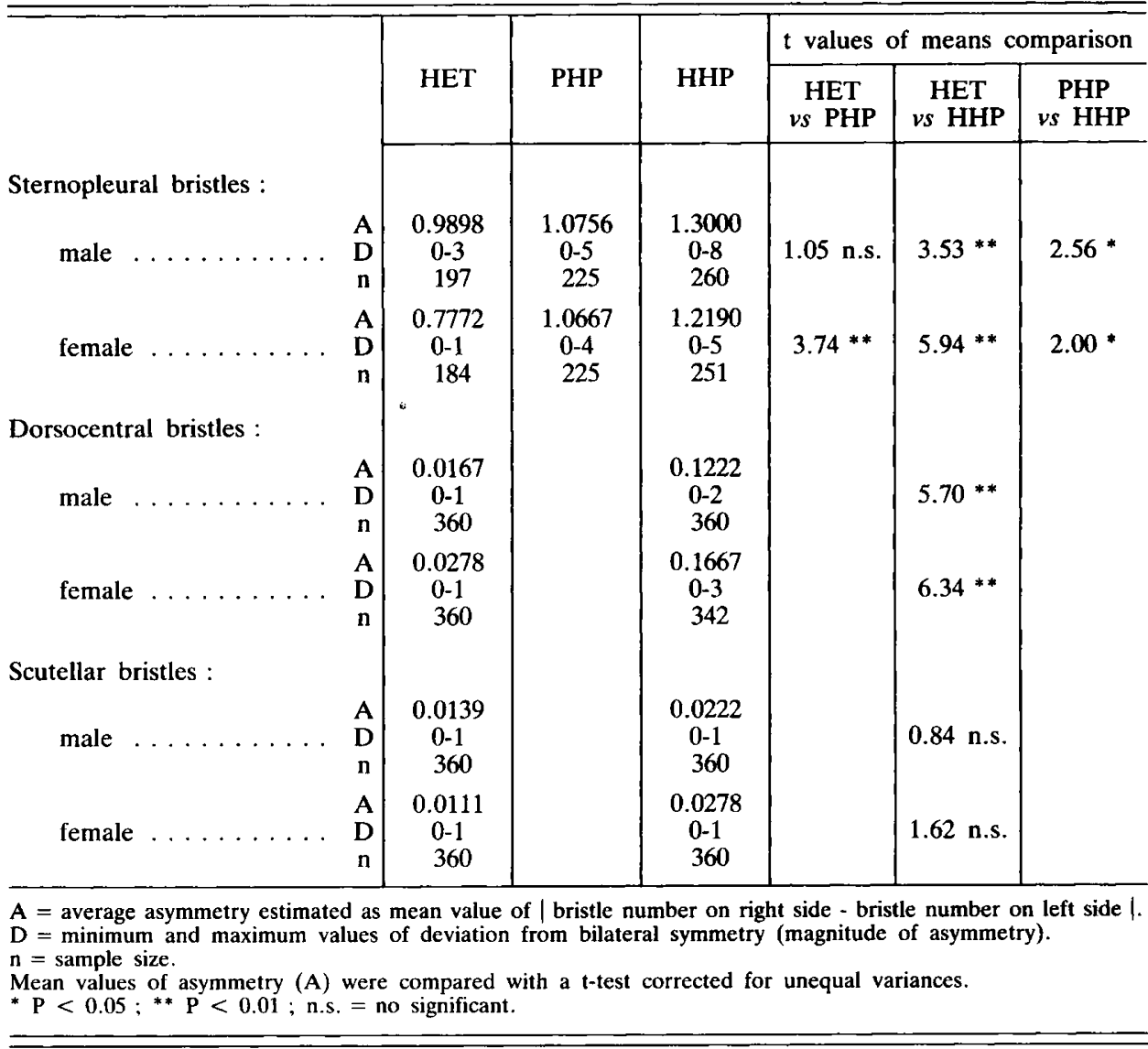

These results are similar to those obtained in other works where it becomes evident that the homozygous individuals show greater variability for morphometric traits (estimated by variance, coefficient of variation, degree of symmetry, etc.) than the ieterozygous (see MiTTON \& GRANT, 1984, for a review).

In our case, when we compared the HET with the homozygous individuals (HHP and PHP), the same tendency was observed : the homozygous showed greater variance and greater asymmetry for the morphometric characters analyzed. However, the differences between HHP and HET were statistically significant in 79 p. 100 of the cases, whereas the differences between PHP and HET were only statistically significant in 33 p. 100 of the comparisons made. 
STERNOPLEURAL BRISTLES
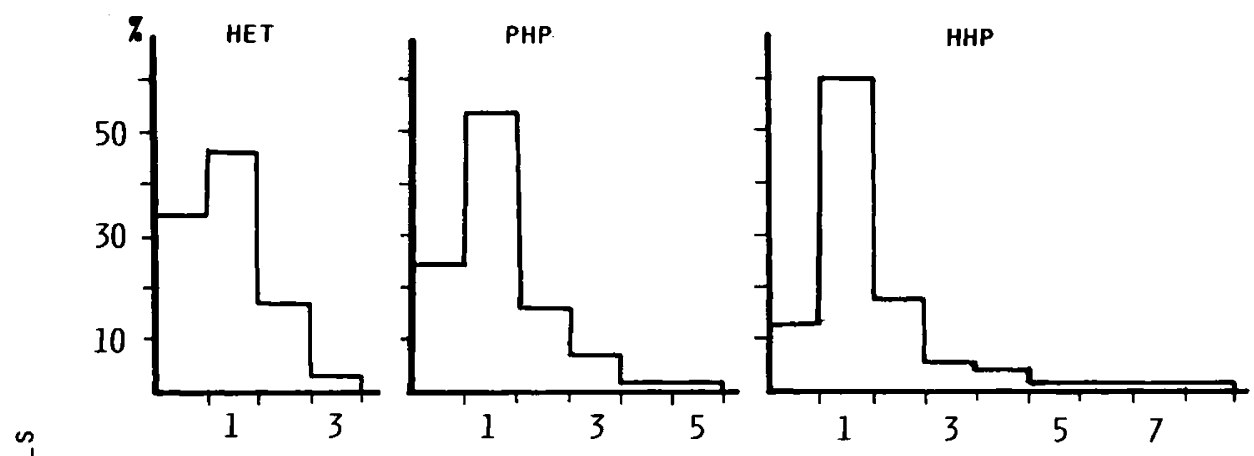

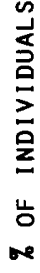
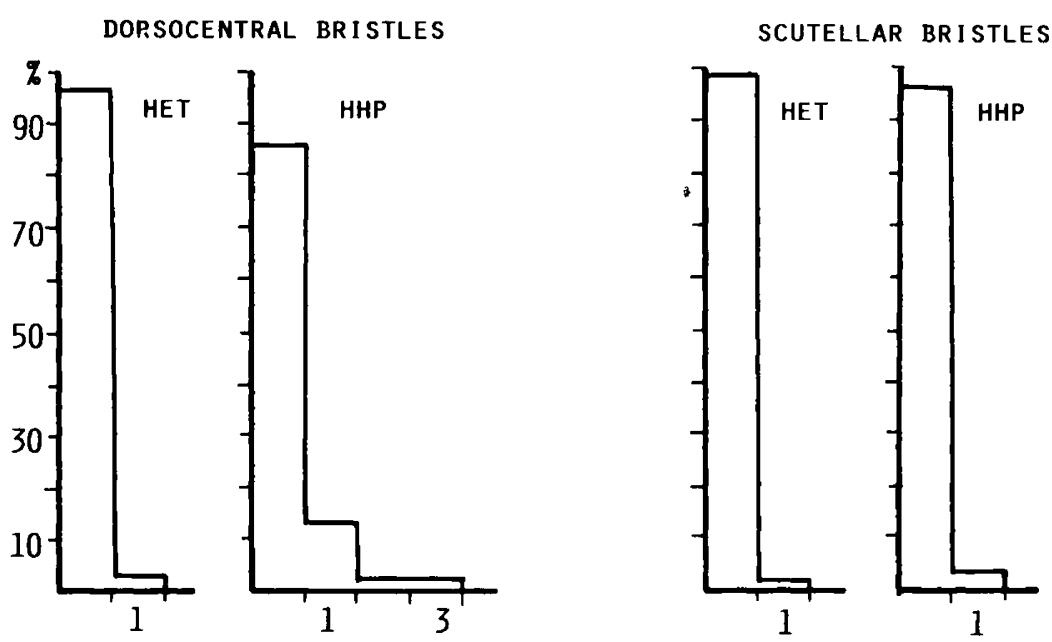

MAGNITUDE OF ASYMMETRY

Fig. 1

Distribution of the magnitude of asymmetry (D).

For graphic representation the values of males and females were pooled.

The HHP differ significantly from the PHP individuals in 66 p. 100 of the cases. These differences were not due to differences in the 5 biochemical loci analyzed (both types of individuals were homozygous for them), but to the homozygosity level of the rest of the genotype (the HHP individuals are totally homozygous for chromosomes II and III, which represent approximately 80 p. 100 of all the genome of $D$. melanogaster, LEWONTIN, 1974).

The comparisons made between HET and PHP individuals were similar in type to those carried out in other works dealing with individuals taken from natural populations. In both cases the individuals were classified according to their level of homozygo- 
sity for some biochemical loci. In our case the differences between HET and PHP were due, fundamentally, to the genetic constitution which these individuals showed for the 5 biochemical loci analyzed. For the rest of genotype there was no evidence to suggest that there were differences between them, because to obtain the PHP and the HET populations, a minimum of 10 or 20 different lines were pooled (see Material and methods). NEI et al. (1975) have demonstrated that a random sample of 10 chromosomes from a natural population permits reconstruction of about $90 \mathrm{p} .100$ of the total genetic variability contained in these natural populations.

The data presented reject the null hypothesis tested here and are consistent with the hypothesis that the higher the homozygosity level the further away these individuals are from the center of the morphological character distribution and from bilateral symmetry.

These relationship between protein heterozygosity and developmental stability appear to be general, but they are certainly not universal (HANDFORD, 1980 ; MCANDREW et al., 1982). Certainly, these relationships are not expected in all characters, Soule (1982) predicts that this relationship is more likely to be found when stabilising selection can be shown to operate on the character analysed. The negative results reported by MCANDREw et al. (1982) in the plaice (Pleuronectes platessa) may fit this prediction. In the present study 2 of the morphological characters (dorsocentral and scutellar bristles) showed a strong canalization in natural populations of $D$. melanogaster, whereas in the other two (sternopleural and fifth abdominal sternite bristles) no stabilising selection can be demonstrated. However, in our case the 2 types of characters showed the same tendency with respect to the enzymatic heterozygosity (tabl. 2 and 3); the HET were less variable and more symmetric than homozygous individuals.

This negative correlation between allozyme heterozygosity and morphological variance and asymmetry may be interpreted in different ways. One interpretation suggests that the biochemical marker loci are linked to genes determining the morphological character ; the observed relationship is caused by linked genes or chromosome segments and not by the enzyme loci alone. This hypothesis does not seem feasible to explain our results because :

a) It is difficult to accept that from among thousands of biochemical loci of Drosophila, 5 of them, chosen at random, are associated with morphological trait loci, also chosen at random.

b) Our synthetic populations have no chromosomal inversion.

c) Linkage disequilibrium is not a common phenomenon in populations of Drosophila; surveys of natural populations generally reveal little or no linkage disequilibrium, and studies in experimental populations reveal that the linkage disequilibrium initially generated by stochastic processes decays quickly (HedRICK et al., 1978 ; CLEGG et al., 1980 ; SANCHEZ \& RuBio).

Another possibility, considered by LEARY et al. (1984), is that the heterozygosity of the enzymes causally influences development. In this case, the effect is due to the enzyme itself. Their results with the locus Ldh-3 of rainbow trout indicate that null allele heterozygotes are more asymmetrical than homozygotes for the active allele and they suggest that the enzyme locus itself is affecting asymmetry. This is not our case, because preliminary results (BLANCo \& RUBIo, 1983) show that the homozygotes for the different electromorphs at individual loci do not differ from each other with respect to any of the morphometric characters utilized in this study. 
Another hypothesis put forward to explain the correlation between heterozygosity and developmental stability is proposed by MrrToN \& KoEHN (1985). They suggest that since during development an organism requires energy for biosynthesis and to face stressful environmental changes, the heterozygotes should be less affected during development by environmental variations since these genotypes are, on the average, in a higher positive energy balance, and because of this the heterozygotes exhibit greater developmental stability. In the data presented here, there are no consistent indications to reject or to accept this hypothesis, but in our opinion it seems more reasonable to explain our results. In fact, the heterozygosity level of the genetic background (HHP vs PHP) as well as the heterozygosity at 5 enzymatic loci (HET vs PHP), show influence on the variability level of morphological characters and we think that this phenomenon is an expression of a general heterozygous effect.

Certainly, more studies on physiology of enzyme polymorphisms are required.

Received May 23, 1985.

Accepted April 18, 1986.

\section{References}

Biemont C., 1983. Homeostasis, enzymatic heterozygosity and inbreeding depression in natural populations of Drosophila melanogaster. Genetica, 61, 179-189.

Blanco G., Rubio J., 1983. Relaciones entre variantes enzimáticas y caracteres cuantitativos en lineas isocromosómicas de D. melanogaster. Proceeding of XIX Jornadas Luso-Españolas de Genética, Coimbra, 20-24 septembre 1983, p. 157, Instituto Botanico Dr. Julio Henriques, Universidade de Coimbra, Coimbra.

Clegg M.T., Kidwell J.F., Horch C.R., 1980. Dynamics and correlated genetic systems. V. Rates of decay of linkage disequilibria in experimental populations of Drosophila melanogaster. Genetics, 94, 217-234.

EANES W.F., 1978. Morphological variance and enzyme heterozygosity in the monarch butterfly. Nature, 276, 263-264.

El-Kassaby Y.A., 1982. Associations between allozyme genotypes and quantitative traits in Douglas-fin (Pseudotsuga menziesii (miirb) Franco). Genetics, 101, 103-115.

Fleischer R.C., Johnston R.F., KutTZ W.J., 1983. Allozymic heterozygosity and morphological variation in house sparrows. Nature, 304, 628-629.

GRELL E.H., 1967. Electrophoretic variants of $\alpha$-glycerophosphate dehydrogenase in Drosophila melanogaster Science, 158, 1319-1320.

Grell E.H., Jacobson K.B., Murphy J.B., 1965. Alcohol dehydrogenase in Drosophila melanogaster. Science, 149, 80.

Gunawan B., 1981. The relationship between quantitative and allozymic variation in $D$. buzzatii. In: Gibson J.B., Oakeshott J.G. (ed), Genetic Studies of Drosophila Populations, 147-157. Australian National University Press, Canberra.

HANDFord P., 1980. Heterozygosity at enzyme loci and morphological variation. Nature, 286, 261262.

Hedrick P., Jain S., Holden L., 1978. Multilocus systems in evolution. In : Hecht M.K., Holden L., Steere W.C., Wallace B. (ed.), Evolutionnary Biology, vol. 11, 101-184. Plenum Press, New York.

Johnson F.M., 1964. Genetic variation of ADH in D. melanogaster. Nature, 204, 906-907.

KAT P.W., 1982. The relationship between heterozygosity for enzyme loci and developmental homeostasis in peripheral populations of aquatic bivalves (Unionidae). Am. Nat., 119, 824832 . 
Knowles P., Mitron J.B., 1980. Genetic heterozygosity and radial growth variability in Pinus contorta. Silvae Genetica, 29, 114-118.

Kobyliansky E., Livshits G., 1983. Relationship between biochemical heterozygosity and morphological variability in human populations. Ann. Hum. Genet., 47, 215-223.

Koenn R.K., Shunway E., 1982. A genetic/physiological explanation for differential growth rate among individuals of the American oyster Crassostrea virginica (Gmelin). Mar. Biol. Lett., 3, 35-42.

Leary R.F., Allendorf F.W., KNUdSen K.L., 1983. Developmental stability and enzyme heterozygosity in rainbow trout. Nature, 301, 71-72.

Leary R.F., Allendorf W.F., KNUdSEn K.L., 1984. Superior developmental stability of heterozygotes at enzyme loci in salmonid fishes. Am. Nat., 124, 540-551.

Leding F.T., GuRIES R.P., Bonefield B.A., 1983. The relation of growth to heterozygosity in pitch pine. Evolution, 37, 1227-1238.

LeRner I.M., 1954. Genetic Homeostasis. 134 pp., Oliver and Boyd, Edinburgh.

LEWONTIN R.C., 1974. The genetic basis of evolutionary change. 346 pp., Columbia University Press, New York.

MCANDREW B.J., WARD R.D., BEARDMORE J.A., 1982. Lack of relationship between morphological variance and enzyme heterozygosity in the plaice Pleuronectes platessa. Heredity, 48, 117-125.

Mirton J.B., 1978. Relationship between heterozygosity for enzyme loci and variation of morphological characters in natural populations. Nature, 273, 661-662.

Mitton J.B., Knowles P., Sturgeon K.B., Linhart Y.B., Davis M., 1981. Associations between heterozygosity and growth rate variables in western forest trees. In: CONCLE M.T. (ed.), Proc. Symp. Isozymes North American Forest Trees and Forest Insects, USDA, General Technical Report PSW-48, 27-34. Washington D.C. : USGPO.

Mitron J.B., Grant M.C., 1984. Associations among protein heterozygosity, growth rate, and developmental homeostasis. Ann. Rev. Ecol. Syst., 15, 479-499.

Mitton J.B., Koенn R.K., 1985. Shell shape variation in the blue mussel Mytilus edulis L., and its association with enzyme heterozygosity. J. Exp. Mar. Biol. Ecol., 90, 73-80.

Nei M., Maruyama T., Chakraborty R., 1975. The bottleneck effect and genetic variability in populations. Evolution, 29, 1-10.

Pierce B.A., Mirton J.B., 1982. Allozymic heterozygosity and growth in the tiger salamander, Ambystoma tigrinum. J. Heredity, 73, 250-253.

Sakal R.K., Tung D.A., Skandalios J.S., 1969. Developmental genetics studies of L-aminopeptidase in Drosophila melanogaster. Mol. Gen. Genet., 105, 24-29.

Sanchez J.A., Rubio J. Evolution du polymorphisme des loci enzymatiques dans des populations expérimentales de Drosophila melanogaster. III. Déséquilibre de liaison entre les loci $A d h$ et $\alpha$-Gpdh (Submitted to Genetica).

SiNGH S.M., Zouros E., 1978. Genetic variation associated with growth rate in the American oyster (Crassostrea virginica). Evolution, 32, 342-345.

SoKal R.R., Rohlf F.J., 1979. Biometria. 483 pp., Edi. Blume, Madrid.

Soule M., 1967. Phenetics of natural populations. II. Asymmetry and evolution in a lizard. Am. Nat., 101, 140-167.

Soule M., 1979. Heterozygosity and developmental stability : another look. Evolution, 33, 396401.

Soule M., 1982. Allomeric variation. 1. The theory and some consequences. Am. Nat., 120, 751764.

VRIJENHOECK R.C., LERMAN S., 1982. Heterozygosity and developmental stability under sexual and asexual breeding systems. Evolution, 36, 768-776.

Wallis B.B., Fox A.S., 1968. Genetic and developmental relationship between two alkaline phosphatases in Drosophila melanogaster. Biochem. Genet., 2, 141.

Wrighr T.R.F., 1963. The genetics of an esterase in Drosophila melanogaster. Genetics, 48, 787801.

Zouros E., Singh S.M., Miles H.E., 1980. Growth rate in oyster : an overdominant phenotype and its possible explanations. Evolution, 34, 856-867. 